\title{
Investigating the Scaling Properties of Extreme Rainfall Depth Series in Oromia Regional State, Ethiopia
}

\author{
Megersa Tesfaye $^{1^{\star}}$ and Solomon Seyoum Demissie ${ }^{2}$ \\ ${ }^{1}$ Department of Hydraulic and Water Resources Engineering, College of Engineering and Technology, \\ Post Box No: 395, Wollega University, Nekemte, Ethiopia \\ ${ }^{2}$ Ethiopian Institute of Water Resources, Akaki Campus, Post Box No: 150461, Addis Ababa, Ethiopia
}

\begin{abstract}
Depth Duration Frequency (DDF) relationships are currently constructed based on at site frequency analysis of rainfall data separately for different durations. These relationships are not accurate and reliable since they depend on assumptions such as distribution selection for each duration; they require a large number of parameters, experience intensive equations and regionalization is also very poor and coarse. In this study, scaling properties of extreme rainfall depth series were examined to establish scaling behavior of statistical moments and quantile estimates over different durations. The annual extreme series of precipitation maxima for storm duration ranging from 0.5 to $24 \mathrm{hr}$ observed at network of rain gauges sited in Oromia regional state were analyzed using an approach based on moments. The analysis investigated the statistical properties of rainfall extremes and detected that the statistics of the rainfall extremes follows a power law relation with its duration. Moreover, the variations of the distribution parameters with durations of annual maximum rainfall depth series were explored and found that the logEV1, EV1 and logistic distribution parameters exhibit a power law relationship with durations. Following the analysis, scale invariance of extreme rainfall depth series is investigated and dissipative (multiple scaling) nature of extreme rainfall depth series is considered, thus introducing a general distribution free framework to develop Depth Duration frequency (DDF) model.
\end{abstract}

\author{
Article Information \\ Article History: \\ Received : 02-06-2014 \\ Revised : 17-09-2014 \\ Accepted : 21-09-2014 \\ Keywords: \\ Scaling Properties \\ Depth Duration Frequency \\ Rainfall Depth Series \\ Multiple Scaling \\ *Corresponding Author: \\ Megersa Tesfaye \\ E-mail:
}

megersatesfaye@gmail.com

\section{INTRODUCTION}

The scaling or scale-invariant models enable us to transform data from one temporal or spatial model to another one and thus, help us to overcome the difficulty of inadequate data. Therefore, investigation of scaling property of extreme rainfall depth series can provide comprehensive statistical description of the rainfall depthduration-frequency relationships. A natural process fulfills the simple scaling property if the underlying probability distribution of some physical measurements at one scale is identical to the distribution at another scale multiplied by a factor that is a power function of the ratio of the two scales. A random rainfall depth series with duration $D$, $R(D)$ exhibits a simple scale invariance behavior if:

$$
\lambda D \stackrel{d}{=} \lambda^{\eta} I(D) \text { holds. }
$$

The equality $=$ refers to identical probability distributions in both sides of the equations; $\lambda$ denotes a scale factor and $\eta$ is a scaling exponent. Strict sense simple scaling property asserts that the probability distributions of extreme rainfall depth series at various durations are scale invariance. Further relaxing this preposition, a wide sense simple scaling extends the scale invariant property to quantiles and moments of the

extreme rainfall depth series. According to a wide sense simple scaling property, the quantile of extreme rainfall depth series is given by:

$$
h_{T}(\lambda D)=\lambda^{\eta} h_{T}(D)
$$

If we take the $1 \mathrm{hr}$ annual maximum rainfall depth as reference duration, the scale factor $(\lambda=D / 1)$ would be equal to the duration of the extreme rainfall depth at consideration. Therefore, the quantile of the extreme rainfall depth that obeys the wide sense simple scaling property could be given by:

$$
h_{T}(D)=D^{\eta} h_{T}(1)
$$

The distribution function used to explain the 1-hr duration extreme rainfall depth series determines the form of the quantile function in Equation (3). Assuming the scaling exponent is independent of recurrence interval, the row moments and probability weighted moments of the extreme rainfall depth series at order $q$ can be respectively given as

$$
\begin{aligned}
& E\left[I^{q}(\lambda D)\right]^{d}=\lambda^{q \eta} E\left[I^{q}(D)\right] \\
& M_{1, q, 0}(\lambda D)=\lambda^{\eta} M_{1, q, 0}(D)
\end{aligned}
$$




\section{Megersa Tesfaye and Solomon Seyoum}

Where the $E[\quad]$ is expected values operator, $q$ is the moment order and $\lambda$ is a scale factor and M1, q, 0 is the probability weighted moment of order $\mathrm{q}$. The random field I(D) exhibits a simple scale invariants in a wide sense if the above equation holds. As already shown in many literatures, further manipulations on the moments in the above equation (4) and (5) implies that the dimensionless central moments(coefficient of variation, coefficient of skewness, coefficient of kurtosis) and the corresponding dimensionless L-moment ratios of extreme rainfall depth series which exhibits wide sense simple scaling property are independent of duration.

Suppose the wide sense simple scaling holds for duration in the range $D_{X} \leq D \leq D_{Y}$ and $D_{*}$ be reference duration within this range.

The reference duration could be the time scale at which the reference rainfall is measured. If the scale factor is defined as $\lambda=D / D_{*}$, then the quantiles of extreme rainfall depth series in equation (2) can be expressed as

$$
h_{T}(D)=\frac{h_{T}\left(D_{*}\right)}{D_{*}^{\eta}} D^{\eta}
$$

Similar power relationships can be deduced from the row moments and probability weighted moments of extreme rainfall depth series as, respectively

$$
E\left[H_{D}^{q}\right]=\frac{E\left[H_{D_{s}}^{q}\right]}{D_{*}^{q \eta}} D^{q \eta}
$$

and

$$
\beta_{q}(D)=\frac{\beta_{q}\left(D_{*}\right)}{D_{*}^{\eta}} D^{\eta}
$$

\section{MATERIALS AND METHODS}

\section{Description of the Study Area}

The study area selected for the study was Oromia regional state which is located between $3^{0} \mathrm{~N}$ to $10.5^{\circ} \mathrm{N}$ latitude and $34^{\circ} \mathrm{E}$ to $43^{\circ} \mathrm{E}$ longitude. It covers an area of $353,690 \mathrm{~km}^{2}$ and accounts for $32 \%$ of the country (population and housing census commission report, 1994). Based on figures from the Central Statistical Agency of Ethiopia (CSA) published in 2005, Oromia has an estimated total population of $26,553,000$. The regional state of Oromia borders Afar and Amhara regional states in the north, Kenya in the south, the regional state of Somali in the east, and the Republic of Sudan and the regional state of Benishangul in the west, and the regional states of Southern Nations and Gambela in the south.

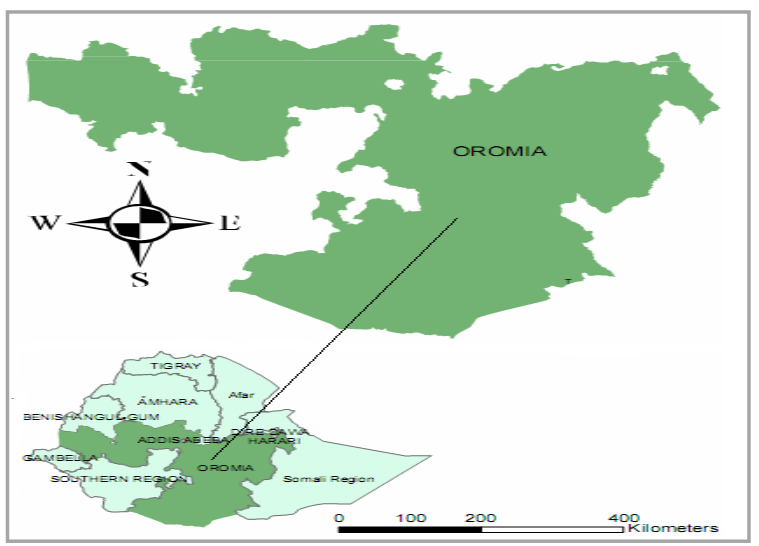

Figure 1: Location of the study area.
Sci. Technol. Arts Res. J., July-Sep 2014, 3(3): 122-131

\section{Material Used}

The materials used for this research were;

- Hourly rainfall data

- Arc GIS to locate the station and delineate the study area

- Spreadsheet/MS Excel 2003 for data analysis and graphical distribution fitting

- Easy fit software for distribution fitting and parameter estimation

\section{Methodology}

It is obvious that a random sample of rainfall data is required prior to the implementation of frequency analysis. The random sample often is an annual maximum series of total rainfall depth with respect to a pre-specified duration (D). Before data collection begins, the pre-specified durations, also known as design duration, are artificially designated which are used to determine the corresponding annual maximum rainfall depth in contrast to event durations which are actual raining periods of time of real storm events. The design duration selected for this study was $0.5,1,2,3,5,6$ and $24 \mathrm{hr}$. From the data base of 55 stations, annual maximum rainfall depth series from 1978 to 2012 having 32 years length was obtained by employing fixed duration technique at each stations in the study area which involves a continuous moving of a window of size $\mathrm{D}$ (duration) along the time axis and selecting the maximum total rainfall values with in the window in each year. After the necessary data were collected, missing rain fall data's were filled and also the collected data series for all stations were checked for consistency, using double mass curve method. The data were also tested for independence and stationarity by a fortran programme based on lag-one serial correlation coefficient test and Wald-Wolfowitz(W-W) respectively. Statistical analysis based on product moments and probability weighted moments was employed to summarize the extreme rainfall data series and to investigate the scaling properties of extreme rainfall depth series in the study region and its efficiency was tested against quantile estimate from logEV1 distribution, observed hourly rainfall depth and empirical IDF estimates previously developed for the region.

\section{RESULT AND DISCUSSION}

\section{Statistical Analysis of Extreme Rainfall Depth Series}

Rainfall statistics of Oromia Regional State were computed using both conventional moments and Lmoment methods. However, L-moment is a powerful and efficient method to compute any statistical parameters, because such methods can give unbiased estimate of sample parameters and also cannot be easily influenced with the presence of outliers (Rao \& Hamed, 2000). Generally, the statistical parameters computed include mean, standard deviation, coefficient of variation/Lcoefficient of variation, coefficient of skewness/Lcoefficient of skewness, and coefficient of kurtosis/Lcoefficient of kurtosis.

\section{Conventional Moments}

Moments about the origin or about the mean are used to characterize probability distributions. Moments about the origin are the expected values of powers of random variables. For distribution with a probability density function $f(x)$, the $r^{\text {th }}$ moment about the origin is given by:

$\mu_{r}=\int_{-\infty}^{\infty} x^{r} f(x) d x, \quad \mu_{1}^{\prime}=\mu=$ mean 
Megersa Tesfaye and Solomon Seyoum

The central moments $\mu$ are computed by:

$\mu_{r}=\int_{-\infty}^{\infty}(x-\mu)^{r} f(x) d x, \quad \mu_{1}=0$

Sample moments $m_{r}^{\prime}$ and $m_{r}$ are given by:

$m_{r}^{r}=\frac{1}{N} \sum_{i=1}^{N} X_{i}^{r}, m_{1}^{\prime}=$ sample mean

$m_{r}=\frac{1}{N} \sum_{i=1}^{N}\left(X_{i}-\bar{X}\right)^{r}, \quad \mathrm{~m}_{1}=0$

These sample moments are often biased and may be corrected (cunnane, 1989)

$$
\begin{gathered}
m_{2}=\frac{1}{N-1} \sum\left(X_{i}-\bar{X}\right)^{2} \\
m_{3}=\frac{N}{(N-1)(N-2)} \sum\left(X_{i}-\bar{X}\right)^{3} \\
m_{4}=\frac{N^{2}}{(N-1)(N-2)(N-3)} \sum\left(X_{i}-\bar{X}\right)^{4}
\end{gathered}
$$

The conventional moment ratios are defined as:

$$
\begin{gathered}
c_{V}=\mu_{2}^{1 / 2} / \mu_{1}^{\prime} \\
C_{s}=\mu_{3} / \mu_{2}^{3 / 2} \\
C_{k}=\mu_{4} / \mu_{2}^{2}
\end{gathered}
$$

Where: $\mathrm{C}_{v}$ - Coefficient of variation; $\mathrm{C}_{\mathrm{s}}$ - coefficient of skewness and $C_{k}-$ Coefficient of kurtosis

\section{L-moments}

L-moments are analogous to conventional moments but are estimated by linear combination of an ordered data set, namely L-statistics (Rao \& Hamed, 2000). Like ordinary product moments, L-moment summarizes the characteristics or shape of theoretical probability distributions and observed samples. Both moment types offer measures of distributional location (mean), scale (variance), skewness (symmetric shape), and kurtosis (flatness). L-moment offer significant advantages over ordinary product moments because of the following reasons:

- L-moment ratio estimators of location, scale, and shape are nearly unbiased, regardless of the probability distribution from which the observations arise (Hosking 1990);

- L-moment ratio estimators of L-C $\mathrm{C}_{v}$ and L-skew do not have bound which depend on a sample size as do the ordinary product moment ratio estimators of $\mathrm{C}_{V}$ and Cskew (Kirby, 1974);

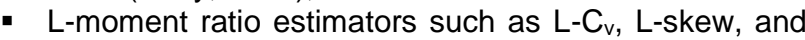
L-Kurtosis can exhibit lower bias than conventional product moment ratio especially for highly skewed samples; and

- L-moment ratio diagrams are particularly good at identifying the distributional properties of highly skewed data, whereas ordinary product moments diagrams are almost useless for this task (Vogel and Fennessey, 1993).

Probability weighted moments (PWMs) introduced by Greenwood et al. (1979) are linear function of L-moments. Accordingly, PWMs are defined as:
Sci. Technol. Arts Res. J., July-Sep 2014, 3(3): 122-131

This can be written as

$$
\beta_{r}=E\left[X\{F(X)\}^{r}\right]
$$

$$
\beta_{r}=\int_{0}^{1} X(F) F^{r} d F
$$

Where $F=F(X)$ is the cumulative distribution function(CDF) for $X, X(F)$ is the inverse CDF of $X$ evaluated at the probability $F$ and $r=1,2,3, \ldots$ is a non negative integer. Where $r=0, \beta_{\circ}$ is equal to the mean of the distribution $\mu=E[X]$

For any distribution the $r^{\text {th }} L-$ moment $\lambda_{r}$ is related to the $r^{\text {th }}$ (PWM) (Hosking, 1990) via;

$$
\lambda_{r+1}=\sum_{k=0}^{r} B_{k}(-1)^{r-k}\left(\begin{array}{l}
r \\
k
\end{array}\right)\left(\begin{array}{c}
r+k \\
k
\end{array}\right)
$$

Moreover the first four L-moments are related to the PWMs using

$$
\begin{aligned}
& \lambda_{1}=\beta_{0} \\
& \lambda_{2}=2 \beta_{1}-\beta_{0} \\
& \lambda_{3}=6 \beta_{2}-6 \beta_{1}+\beta_{0} \\
& \lambda_{4}=20 \beta_{3}-30 \beta_{2}+12 \beta_{1}-\beta_{0}
\end{aligned}
$$

Hosking (1990) defined the L-moment ratio as follows:

$$
\begin{gathered}
\mathrm{L}_{\mathrm{cv}}=\tau_{2}=\lambda_{2} / \lambda_{1} \\
\text { L-skew }=\tau_{3}=\lambda_{3} / \lambda_{2} \\
\text { L-kurtosis }={ }_{4}=\lambda_{4} / \lambda_{2}
\end{gathered}
$$

L-moment ratio diagrams can be used to compare sample estimates of the dimensionless L-moments ratios with their theoretical counterparts. The sample product moments and L-moment ratio statistics were estimated from the annual maximum rainfall depth series at all stations and also from their logarithmic transformations. To compute these parameters, spread-sheet (Excel), was used. These parameters were plotted against their time scale for each station and the result confirmed that the statistics varies with duration at all station for both product moments and L-moments (Figure 2, 3 and 4). Later on, these statistics are very important for the selection of the distribution and investigating the scaling property of maximum rainfall depth series in the study region. More over no specific trend or relation were obtained between the statistics of extreme rainfall depth series and elevation. The random variation of the statistics with elevation and its spatial variation over the study region are observed from the statistics versus elevation plot (Figure 4) and map of L-statistics (Figure 5) respectively.

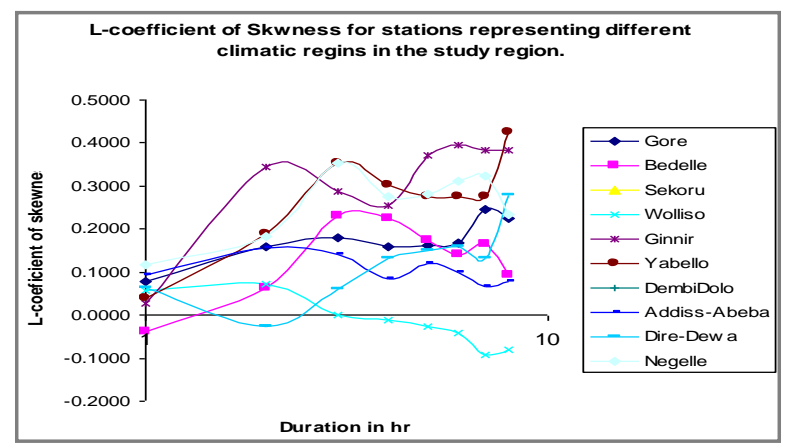

Figure 2: the L-moment ratio (L-coefficient of variation) of maximum rainfall depth series at various durations for sample stations representing different climatic regions in the study area. 
Megersa Tesfaye and Solomon Seyoum

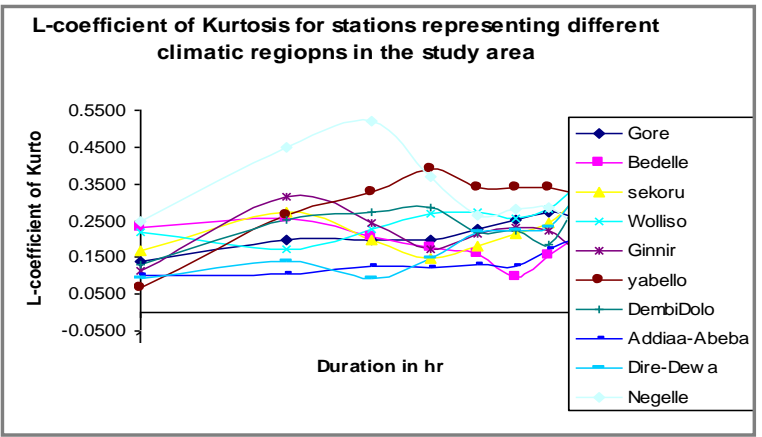

Figure 3: The L-moment ratio (L-coefficient of skewness) of maximum rainfall depth series at various durations for sample stations representing different climatic regions in the study area

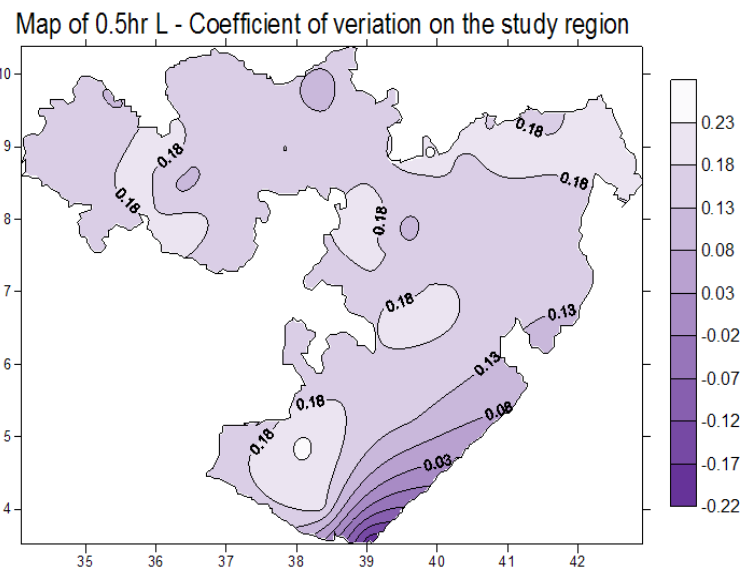

Map of $0.5 \mathrm{hr} \mathrm{L}$ - Coefficient of Skewness on the study region

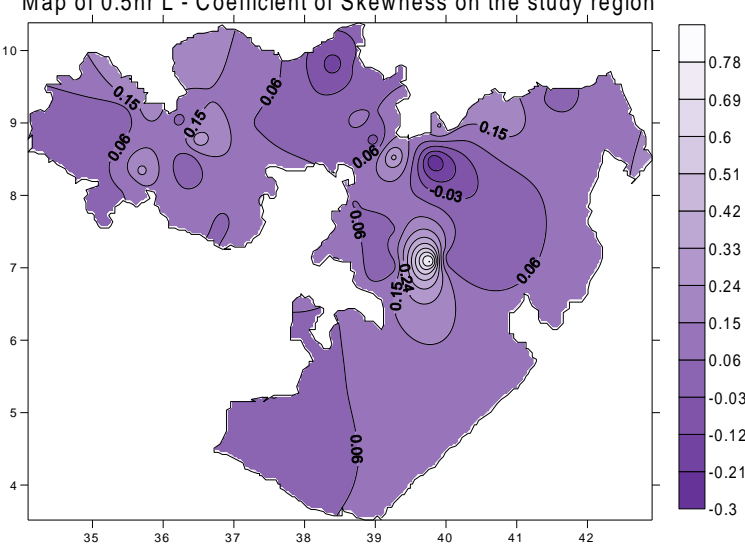

Map of $0.5 \mathrm{hr} \mathrm{L}$ - Coefficient of Kurtosis on the study region

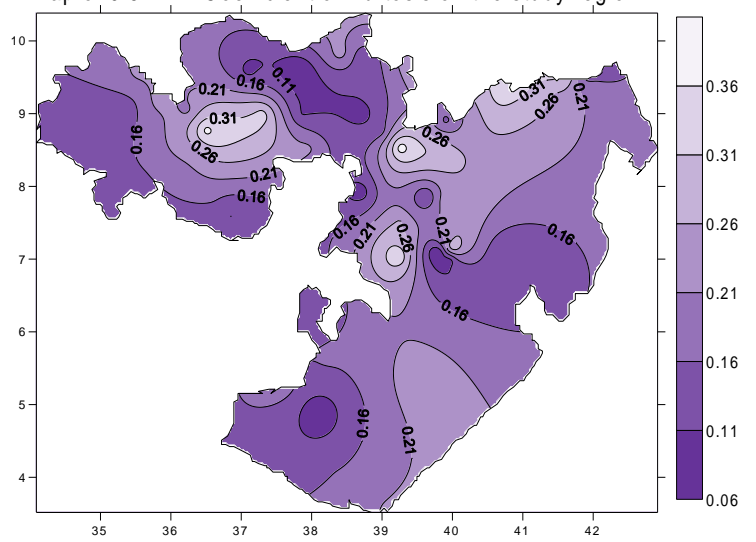

Sci. Technol. Arts Res. J., July-Sep 2014, 3(3): 122-131

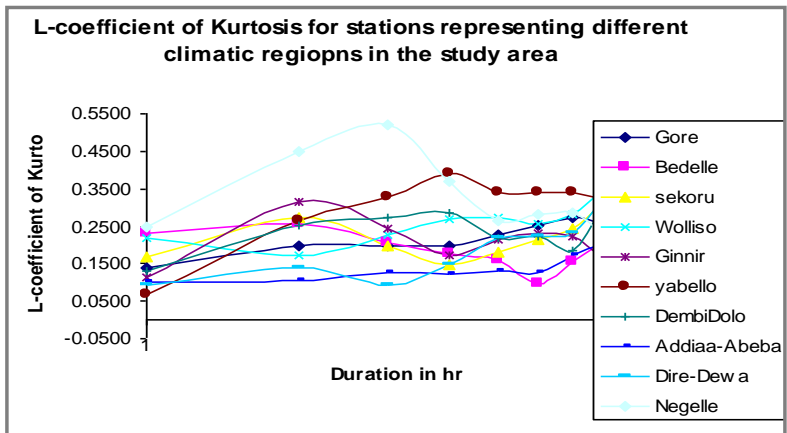

Figure 4: The L-moment ratio (L-coefficient of Kurtosis) of maximum rainfall depth series at various durations for sample stations representing different climatic regions in the study area.
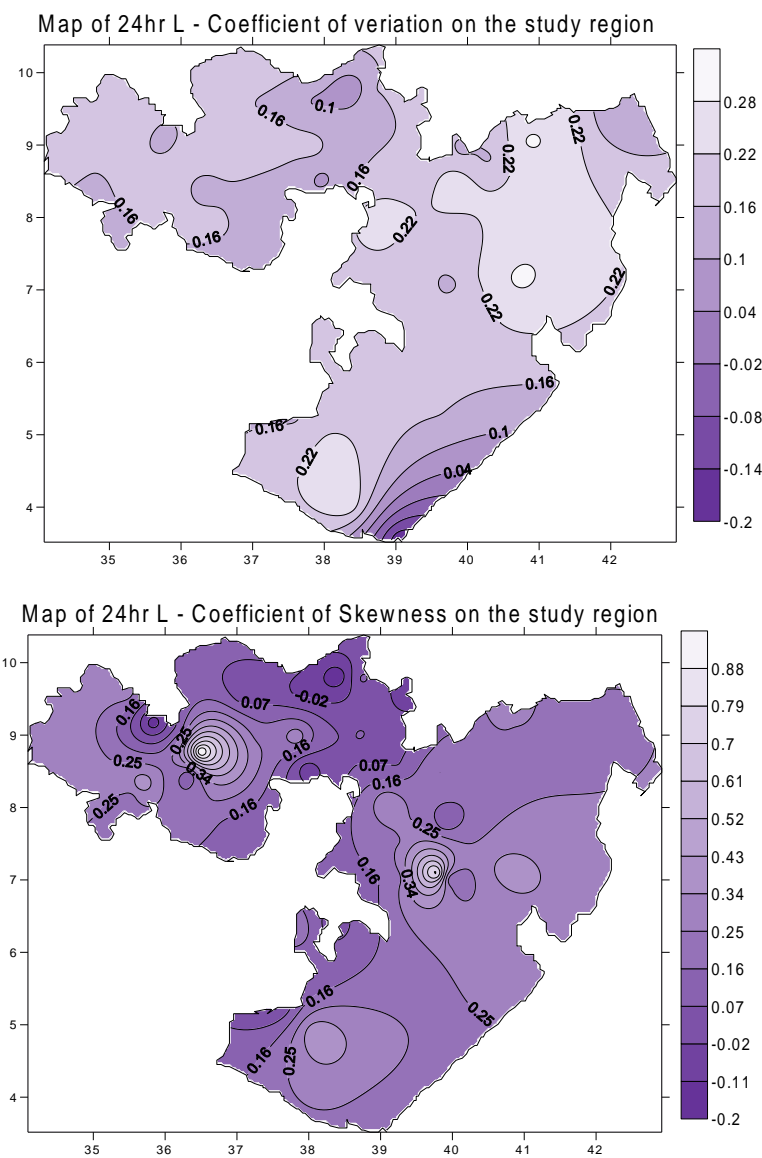

Map of $24 \mathrm{hr} \mathrm{L} \mathrm{-} \mathrm{Coefficient} \mathrm{of} \mathrm{Kurtosis} \mathrm{on} \mathrm{the} \mathrm{study} \mathrm{region}$

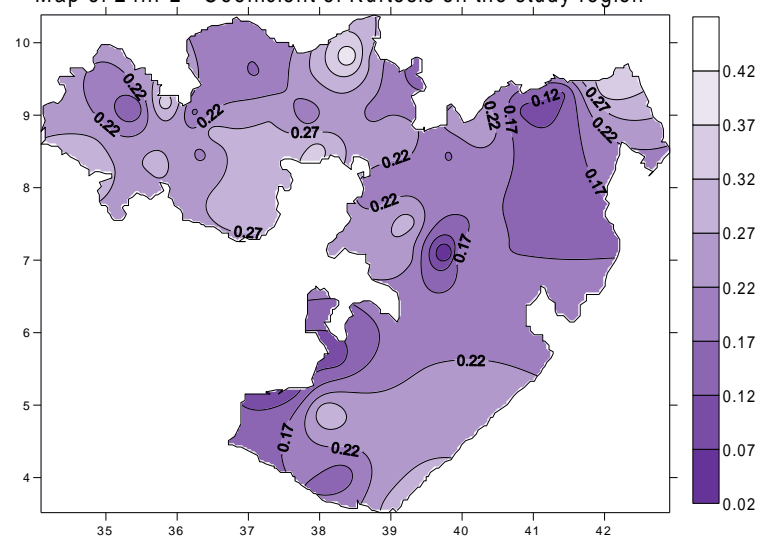

Figure 5: Maps of $0.5 \mathrm{hr}$ and 24hr L-statistics in the study area 
Megersa Tesfaye and Solomon Seyoum

\section{Investigating the Scaling Property of Extreme Rainfall} Depth Series

The scaling property of rainfall in the study region was investigated by computing the moments of extreme rainfall depth series and then by examining the log-log plots of the moments against their duration. The analysis was performed on annual maximum rainfall depth series for storm duration from $0.5 \mathrm{hr}$ to $24 \mathrm{hr}$ rainfall at all stations. The logarithmic plots of the row moments and the probability weighted moments versus duration for different moment orders at all stations confirmed the existence of

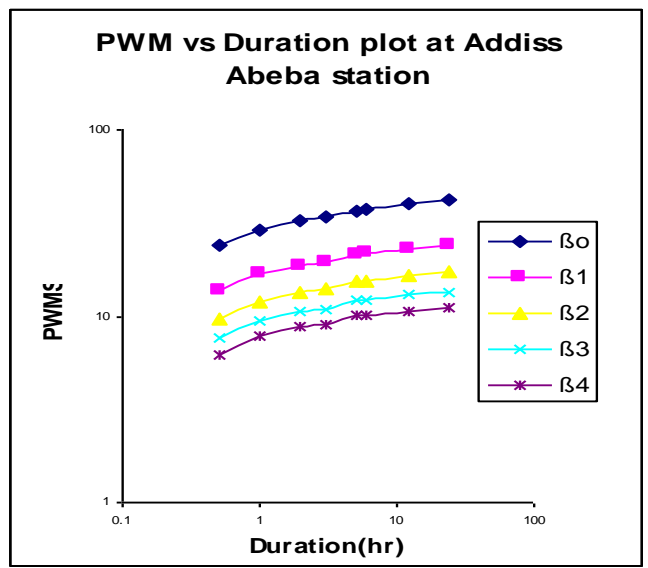

(a)
Sci. Technol. Arts Res. J., July-Sep 2014, 3(3): 122-131

power law scaling. For illustration purpose, both the product (conventional) moments and linear moments of extreme rainfall depth series is plotted against their duration in (Figure 6 )for Addis Ababa station. This confirms the existence of power law scaling which indicates scaling is applicable in the study region. Therefore, the scaling exponent can be estimated from either the row moments or from the probability weighted moments of the extreme rainfall depth series at various durations in the study region.

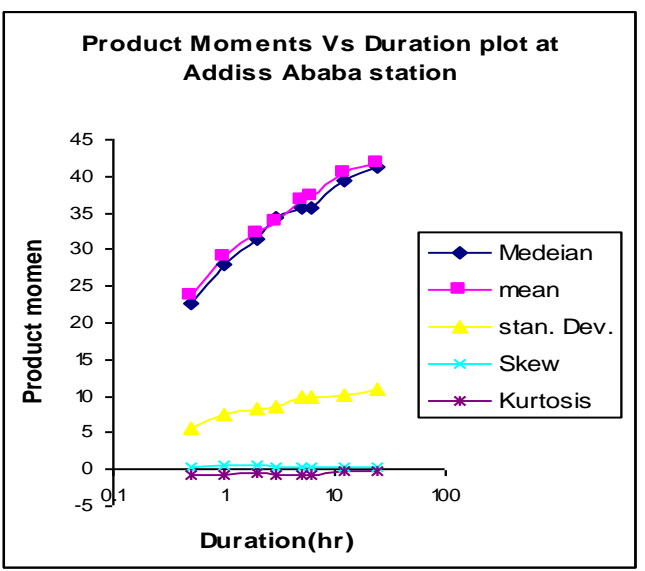

(b)

Figure 6: Plot of PWM moments (a) and product moments (b) at Addis Ababa station

Moreover, simple scaling and multi-scaling properties are also deducted in terms of statistical moments. In order to determine if the data follows simple scaling or multiscaling, the scaling exponent was plotted versus the moment order. As illustrated in Figure 7, the scaling exponent decreases with the moment order at all stations in the study area; and there exists a non-linear relationship between scaling exponent and order of moments. This observation is against the hypothesis of simple scaling theory, and therefore it implies that the property of wide sense simple scaling property of extreme rainfall depth series does not obeyed in the study region.

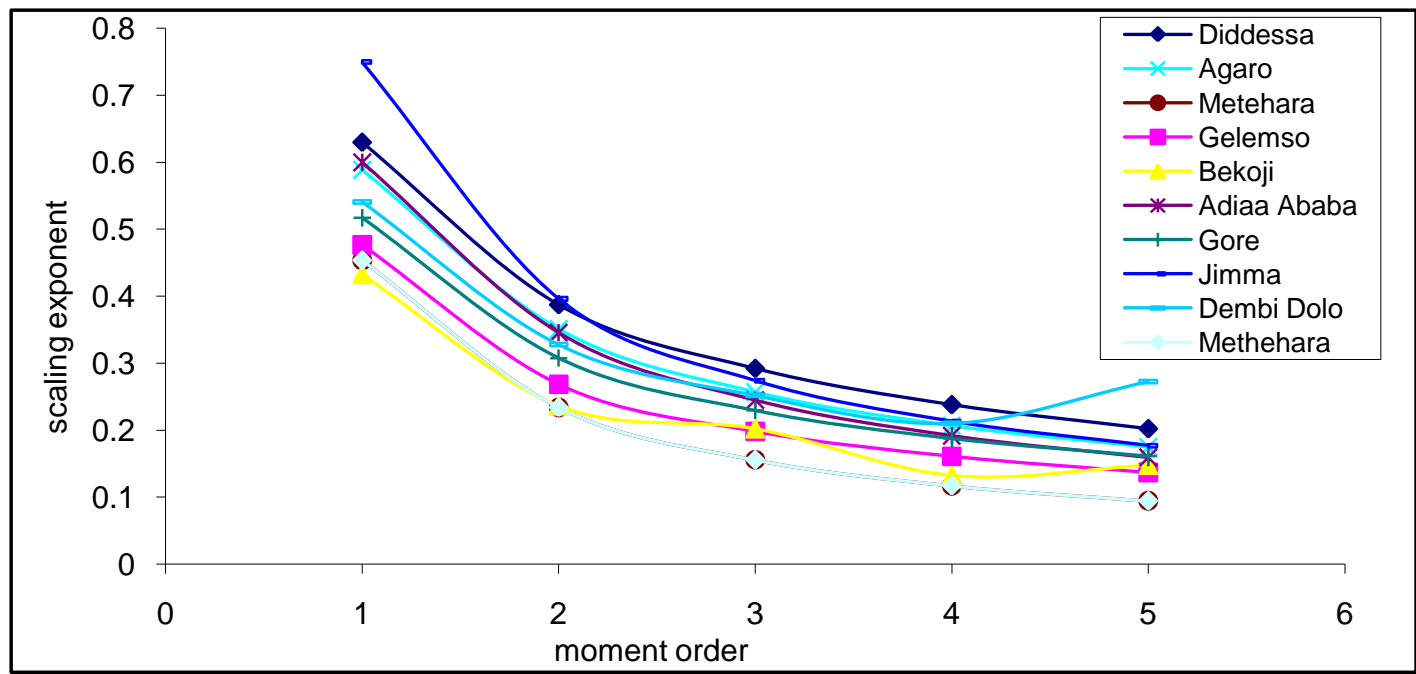

Figure 7: Plot of the scaling exponent versus moment orders of extreme rainfall depth series for sample stations representing different climatic regions

Moreover, the dimensionless central moments (coefficient of variation, skewness, and kurtosis) and the corresponding L-moment ratios of extreme rainfall depth series were drawn and plotted against their duration for all stations. The result shows that dimensionless moment ratios vary with duration for all stations which is against the deduction of wide sense simple scaling theory. Therefore, statistical investigation revealed that the rainfall exhibits multi-scaling property at all stations. The variation of scaling exponent with moment order (Figure 7) may arise from the dependence of scaling exponent on the recurrence interval or duration. In order to investigate the interactions between scaling exponent and recurrence interval, the scaling exponent of annual rainfall depth at all ranks of ascending order at each station were estimated from the scaling quantile relationship of extreme rainfall depth series. The EV1 reduced variate, which is a function of recurrence interval, corresponding to the 


\section{Megersa Tesfaye and Solomon Seyoum}

scaling exponent of each rank of annual rainfall depth was determined from plotting position formula of the ranked extreme rainfall depth series at each station. The variation of scaling exponent with reduced variate is against the deductions of the simple scaling theory that reveals the deviation of the property of the extreme rainfall depth series in the study region from simple scaling behavior as shown in Figure 8.

Moreover, as already explained the dimensionless statistics of extreme rainfall depth series are significantly varies with duration. The variation of scaling exponent
Sci. Technol. Arts Res. J., July-Sep 2014, 3(3): 122-131

with moment order (Figure 7) and recurrence interval (Figure 8) revealed that the annual maximum rainfall depth series are rather exhibiting a wide sense multiple scaling behavior. As already stated in many literatures the quantile function for extreme rainfall depth series exhibiting multiple scaling is given by;

$$
h_{T}(D)=\frac{h_{T}\left(D_{*}\right)}{D_{*}^{\delta+y_{T}}} D^{\delta+\eta_{T}}
$$

Where $D_{*}$ is the scale at which reference rainfall is measured.

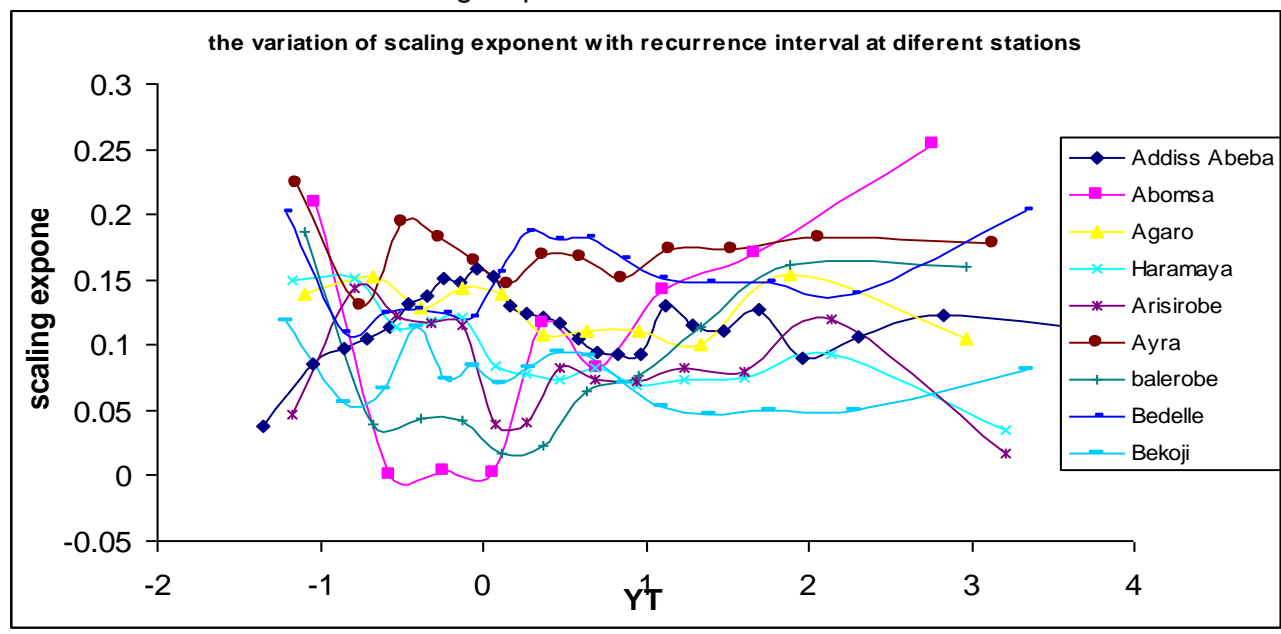

Figure 8: Variation of scaling exponent with EV1 reduced variate

The variation of distribution parameter with durations of annual maximum rainfall depth series are explored for three parameter Log-logistic, two parameter log-logistic, logistic, generalized extreme value, logEV1 and EV1 distributions at fifty five stations in the study region. The method of maximum likelihood is applied for parameter estimation at all stations and for all duration. Graphical evaluation shows that no relationship is observed between the parameter of Log-logistic three parameter distributions and its duration at all stations. All the three parameters (shape, scale and location) parameters are not related to duration (Figure 9). Regarding the two parameter log-logistic distribution, its location parameter exhibits strong power law relation with duration but its scale parameter is not related to duration rather it is more or less constant across duration at all stations.
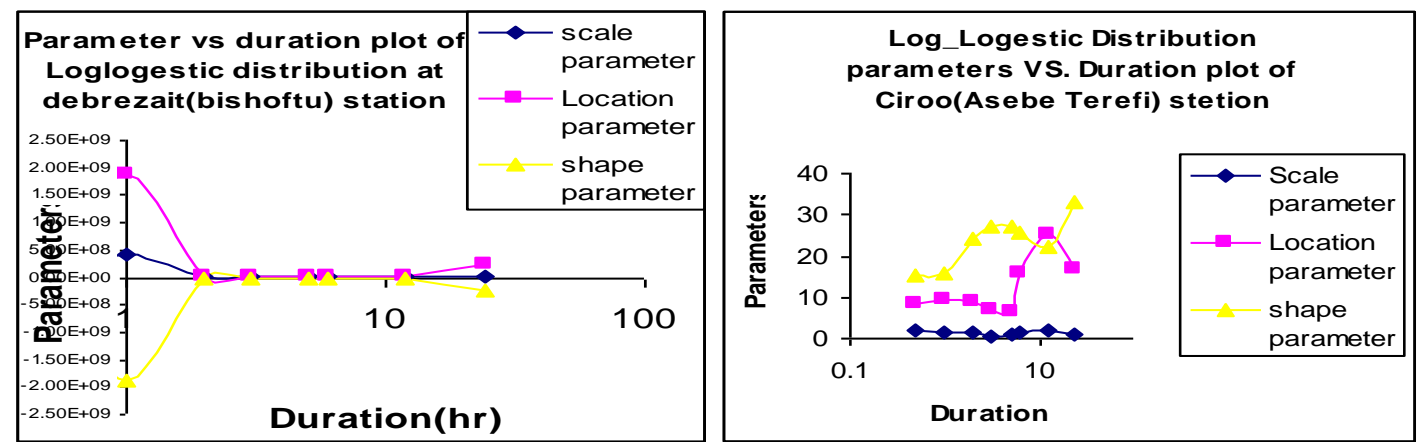

Figure 9: Parameter versus duration plot for three parameter log-logistic distribution
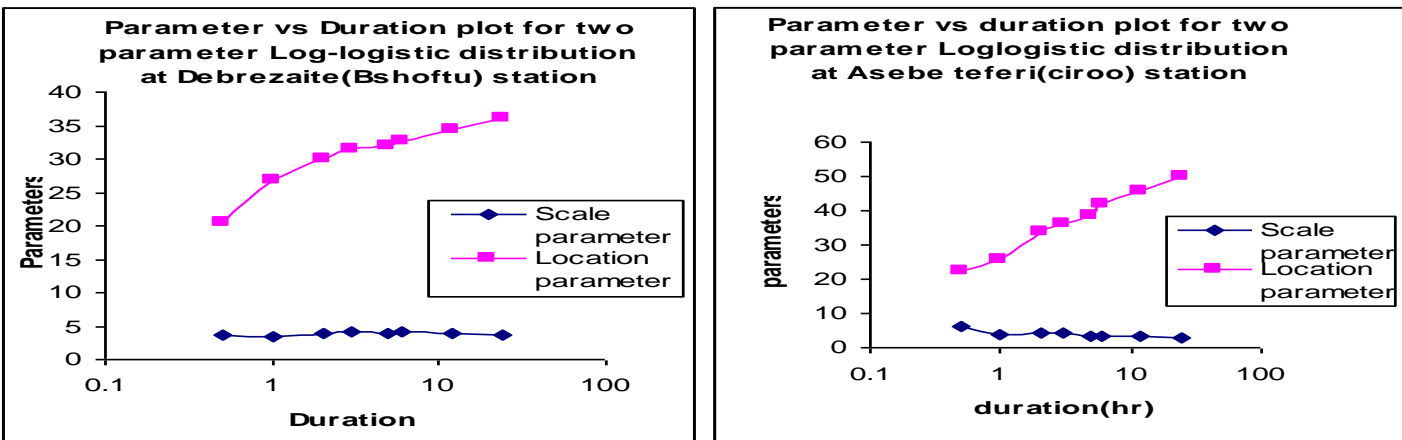

Figure 10: Plot of parameters versus duration for two parameter log-logistic distribution. 


\section{Megersa Tesfaye and Solomon Seyoum}

In the case of generalized extreme value distribution, location parameter exhibited strong relation with duration and scale parameter weakly related to duration while
Sci. Technol. Arts Res. J., July-Sep 2014, 3(3): 122-131

shape parameter did not exhibit power law relation with duration for all stations in the study region. (Figure 11).
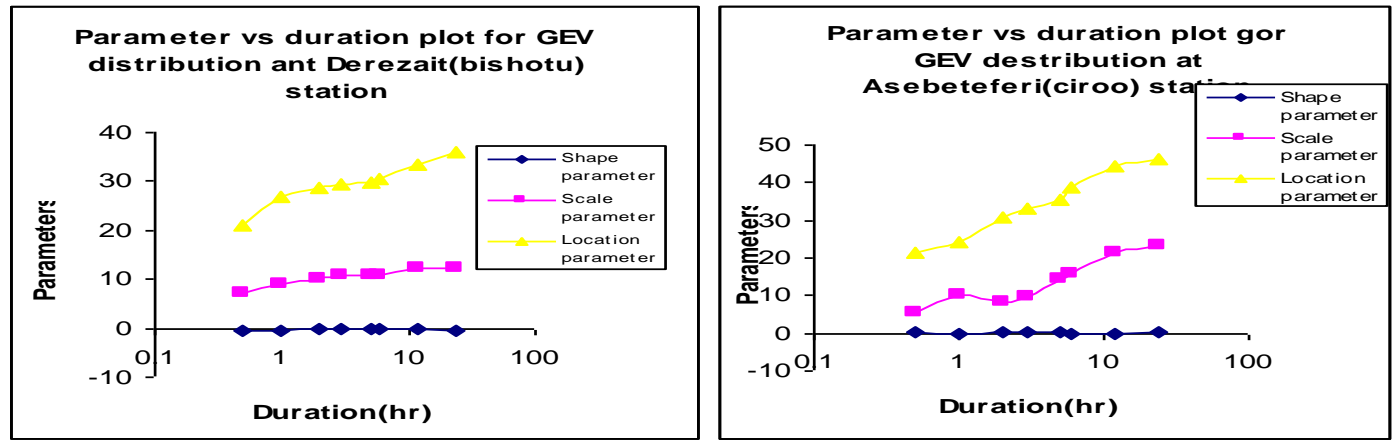

Figure 11: Plot of parameters versus duration for generalized extreme value distribution

The EV1, Logistic and logEV1 distribution parameters exhibited power law relationships with duration for all

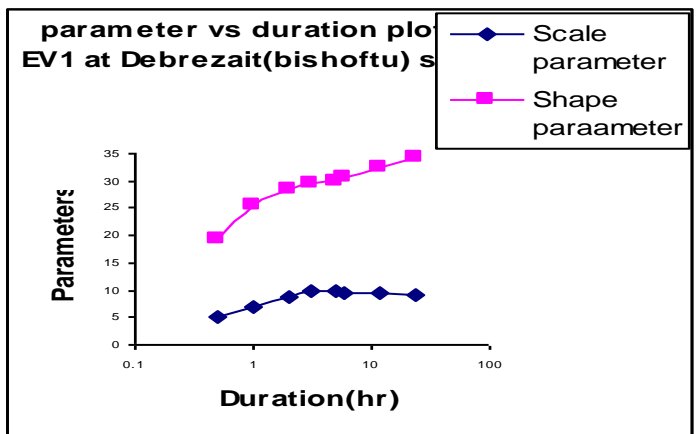

stations. Sample result for few station is shown in figures 12,13 and 14 respectively.

\section{Parameter vs duration plot for}

EV1 at Asebeteferi(ciroo)station
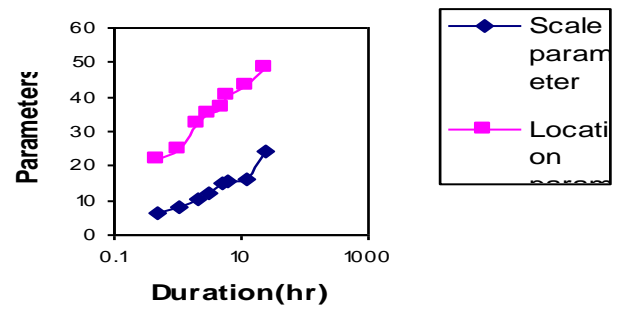

Figure 12: Plot of parameters versus duration for EV1 distribution
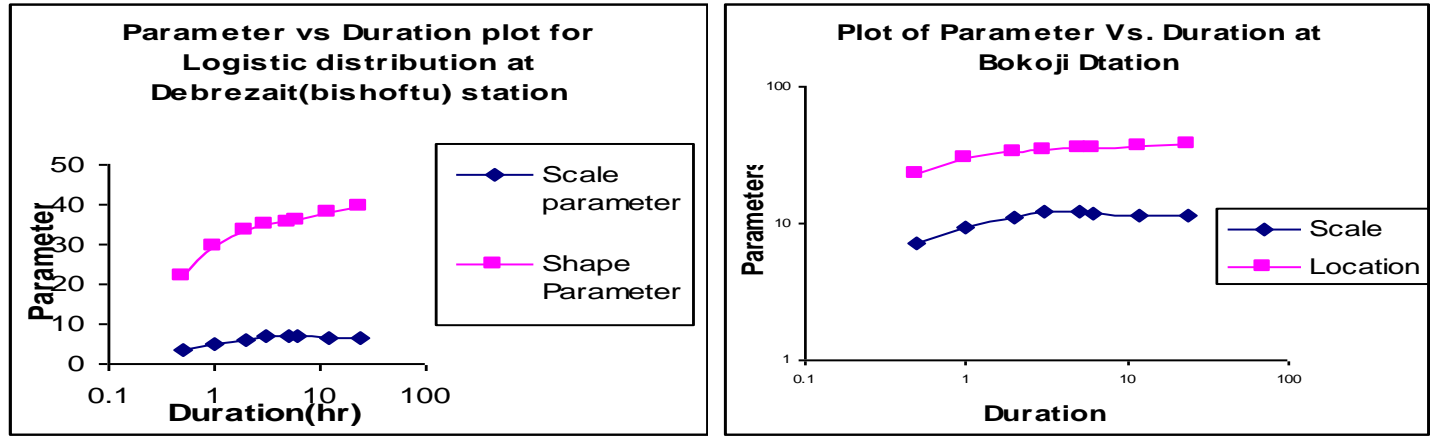

Figure 13: Plot of parameter versus duration for logistic distribution
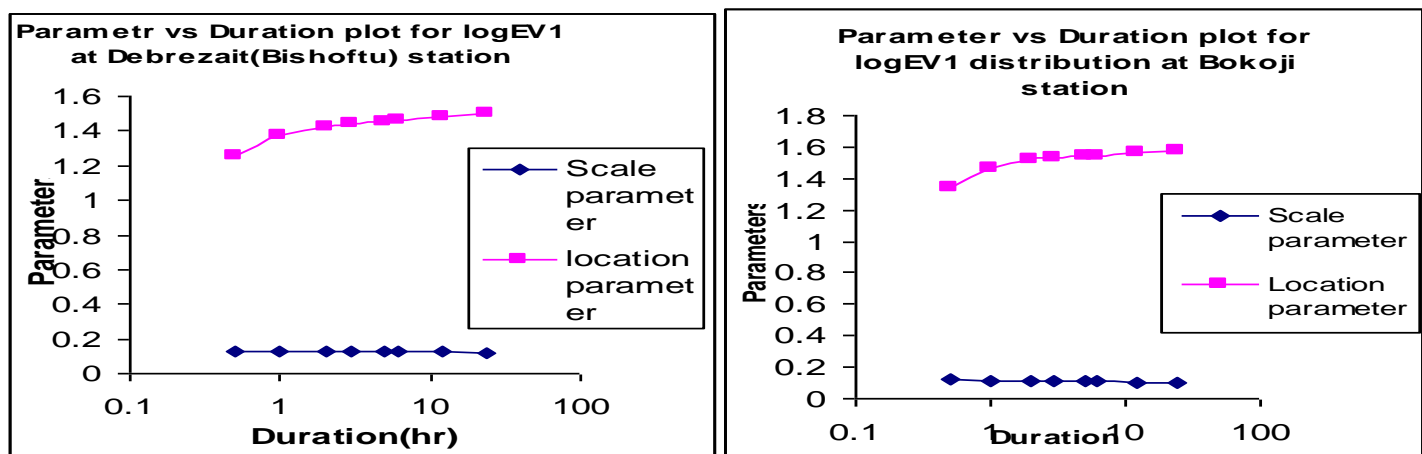

Figure 14: Plot of parameter versus duration for logEV1 distribution

Scaling of the parameters of Logistic, EV1, and logEV1 distribution functions revealed that the parameterduration scaling properties of extreme rainfall depth series may be explained by these distributions. However the statistical summary of the extreme rainfall depth series shows that the dimensionless coefficient of skewness( conventional skewness coefficient and L-coefficient of skewness) are vary from zero which is against the 
Megersa Tesfaye and Solomon Seyoum

hypothesis of extreme events following logistic distribution which have a theoretical skewness coefficient of zero. Therefore further investigation will be undertaken on EV1 and logEV1 distributions.

The dependence of EV1 parameters on the duration of the annual maximum rainfall depth series can be expressed as:
Sci. Technol. Arts Res. J., July-Sep 2014, 3(3): 122-131

$$
\xi=\psi D^{\phi} \text { and } \quad \alpha=\beta D^{\rho}
$$

Where $\xi$ and $\alpha$ are respectively location and scale parameters for EV1 distribution. $\psi, \phi, \beta, \rho$ are coefficients ;whose coefficients and goodness of fit measures for fifty five stations in the study region are given below.

Table 1: The coefficients and goodness of fit criteria of parameter-duration relationship for EV1 distribution

\begin{tabular}{|c|c|c|c|c|c|c|}
\hline \multirow{3}{*}{ Stations } & \multicolumn{4}{|c|}{ Coefficients and efficiency } & \multirow{2}{*}{\multicolumn{2}{|c|}{ Scale, $\alpha$}} \\
\hline & \multicolumn{3}{|c|}{ Location, $\xi$} & & & \\
\hline & $\psi$ & $\phi$ & $\mathbf{R}^{2}$ & $\beta$ & $\rho$ & $\mathbf{R}^{2}$ \\
\hline Abomsa & 26.579 & 0.118 & 0.86 & 6.8805 & 0.3111 & 0.9412 \\
\hline Adama & 24.003 & 0.1614 & 0.96 & 7.0646 & 0.1844 & 0.7656 \\
\hline Addiss Abeba & 25.071 & 0.1409 & 0.9526 & 5.5413 & 0.1579 & 0.865 \\
\hline Agaro & 21.246 & 0.1657 & 0.8508 & 6.1186 & 0.129 & 0.4944 \\
\hline Ambo & 15.705 & 0.2131 & 0.9425 & 4.1894 & 0.2471 & 0.9064 \\
\hline Arisi Adele & 19.176 & 0.1578 & 0.9648 & 5.358 & 0.2081 & 0.7071 \\
\hline Arisi Robe & 26.243 & 0.104 & 0.9813 & 9.4232 & 0.1315 & 0.5147 \\
\hline Arjo & 27.928 & 0.2119 & 0.851 & 5.5016 & 0.3708 & 0.8112 \\
\hline Asossa & 25.771 & 0.1919 & 0.8741 & 6.3347 & 0.068 & 0.165 \\
\hline Awassa & 32.495 & 0.0848 & 0.8835 & 9.4763 & 0.1413 & 0.652 \\
\hline Ayira & 30.807 & 0.2029 & 0.9512 & 7.7986 & 0.1986 & 0.7986 \\
\hline Bale-Robe & 22.552 & 0.1256 & 0.7919 & 5.1869 & 0.2305 & 0.9276 \\
\hline Bedelle & 27.249 & 0.1533 & 0.9735 & 4.6733 & 0.2078 & 0.906 \\
\hline Bekoji & 28.711 & 0.1117 & 0.7974 & 9.3539 & 0.1038 & 0.5427 \\
\hline Ciroo & 26.218 & 0.2114 & 0.9682 & 8.2872 & 0.3293 & 0.9768 \\
\hline Debre-Brehan & 19.077 & 0.1898 & 0.9872 & 5.3943 & 0.2101 & 0.9198 \\
\hline Debre-Markos & 23.392 & 0.1403 & 0.9245 & 8.467 & 0.2329 & 0.7014 \\
\hline Deder & 25.705 & 0.1462 & 0.911 & 7.3769 & 0.2556 & 0.915 \\
\hline Degehabour & 26.533 & 0.0869 & 0.9694 & 8.6101 & 0.0642 & 0.5739 \\
\hline Dembi-Dolo & 26.208 & 0.1239 & 0.8162 & 4.5672 & 0.1511 & 0.6912 \\
\hline Didessa & 26.125 & 0.1372 & 0.8872 & 8.5058 & 0.1562 & 0.8308 \\
\hline Dilla & 31.337 & 0.1435 & 0.959 & 8.3743 & 0.1953 & 0.9414 \\
\hline Diredewa & 24.044 & 0.0981 & 0.8763 & 5.6389 & 0.0796 & 0.4163 \\
\hline Fiche & 26.925 & 0.1579 & 0.9567 & 6.0113 & 0.1291 & 0.7675 \\
\hline Garba-Guracha & 29.052 & 0.0577 & 0.9728 & 3.5241 & -0.0298 & 0.1564 \\
\hline Gelemso & 26.039 & 0.1042 & 0.8331 & 9.1497 & 0.1776 & 0.7686 \\
\hline Gewane & 29.459 & 0.2108 & 0.8785 & 7.9754 & 0.0761 & 0.1096 \\
\hline Gimbi & 23.425 & 0.1161 & 0.8278 & 6.1998 & 0.3776 & 0.9148 \\
\hline Ginnir & 19.354 & 0.1759 & 0.9446 & 6.076 & 0.0607 & 0.2179 \\
\hline Goba & 29.935 & 0.0945 & 0.9335 & 6.8904 & 0.1214 & 0.8585 \\
\hline Gore & 21.61 & 0.1837 & 0.9015 & 5.1043 & 0.2151 & 0.7683 \\
\hline Harere-Mariam & 29.655 & 0.129 & 0.9488 & 7.6495 & -0.0335 & 0.3271 \\
\hline Haramaye & 22.533 & 0.1498 & 0.8088 & 4.7438 & 0.1969 & 0.7855 \\
\hline Hunte & 29.132 & 0.123 & 0.7848 & 4.834 & 0.155 & 0.6809 \\
\hline Hurso & 26.854 & 0.1758 & 0.9098 & 7.4831 & 0.1486 & 0.8738 \\
\hline Humuru & 22.639 & 0.1677 & 0.9299 & 3.9335 & 0.2827 & 0.795 \\
\hline ljaji & 27.797 & 0.1494 & 0.9684 & 5.3341 & 0.1158 & 0.7037 \\
\hline Jimma & 27.404 & 0.1426 & 0.9047 & 5.0903 & 0.0194 & 0.0974 \\
\hline Kachisse & 26.061 & 0.1036 & 0.9258 & 5.4836 & 0.0747 & 0.8367 \\
\hline Konso & 23.367 & 0.11 & 0.7337 & 7.814 & 0.2083 & 0.8246 \\
\hline Kulumsa & 20.649 & 0.1437 & 0.9358 & 6.8723 & 0.2672 & 0.901 \\
\hline Mega & 24.056 & 0.1433 & 0.8392 & 7.6233 & 0.0137 & 0.137 \\
\hline Methehara & 24.585 & 0.1684 & 0.9782 & 7.7455 & 0.1487 & 0.6884 \\
\hline Mierab-Abaya & 27.209 & 0.0549 & 0.8955 & 9.3078 & 0.1611 & 0.7722 \\
\hline Miesso & 29.103 & 0.1669 & 0.8781 & 7.0868 & 0.0659 & 0.2269 \\
\hline Moyalle & 27.064 & 0.0829 & 0.7617 & 5.0343 & 0.1545 & 0.7182 \\
\hline Negelle & 27.058 & 0.1931 & 0.9845 & 6.613 & 0.2236 & 0.7284 \\
\hline Shambu & 20.015 & 0.2553 & 0.9453 & 7.2554 & 0.2478 & 0.8521 \\
\hline Sinana & 28.437 & 0.1314 & 0.9294 & 6.4445 & 0.0462 & 0.4517 \\
\hline Sokoru & 18.869 & 0.0965 & 0.8109 & 6.2187 & 0.125 & 0.7318 \\
\hline Yabello & 23.783 & 0.1421 & 0.9046 & 7.378 & 0.2013 & 0.9185 \\
\hline Zeway & 23.818 & 0.1246 & 0.9149 & 7.4279 & 0.245 & 0.9258 \\
\hline
\end{tabular}

More over the semi-log plot in figure 14 revealed that the $\log E V 1$ distribution parameters are also related to the durations of extreme rainfall depth series at all stations.
The relationships between extreme rainfall durations and the locations and scale parameters of logEV1 distribution can be expressed respectively as

$$
\omega=\log \left(\sigma D^{\delta}\right) \text { and } \varphi=\log \left(\theta D^{x}\right)
$$


Megersa Tesfaye and Solomon Seyoum

where; $\omega$ and $\varphi$ are location and scale parameters of $\log \mathrm{EV} 1$ distribution and $\sigma, \delta, \theta, \chi$ are coefficients whose
Sci. Technol. Arts Res. J., July-Sep 2014, 3(3): 122-131

coefficient and goodness of fit measures at all stations are given below

Table 1: The coefficients and goodness of fit criteria of parameter-duration relationships for logEV1 distribution.

\begin{tabular}{|c|c|c|c|c|c|c|}
\hline \multirow[b]{3}{*}{ Stations } & \multicolumn{6}{|c|}{ Coefficients and Efficiency } \\
\hline & \multicolumn{2}{|c|}{ Location, $\omega$} & \multirow[b]{2}{*}{$\mathbf{R}^{2}$} & \multicolumn{2}{|c|}{ Scale, $\varphi$} & \multirow[b]{2}{*}{$\mathbf{R}^{2}$} \\
\hline & $\sigma$ & $\delta$ & & $\theta$ & $\chi$ & \\
\hline Abomsa & 1.4314 & 0.0262 & 0.8641 & 0.1086 & 0.0917 & 0.6047 \\
\hline Adama & 1.374 & 0.0459 & 0.9445 & 0.0853 & -0.2809 & 0.8403 \\
\hline Addiss Abeba & 1.3865 & 0.0417 & 0.9438 & 0.0885 & 0.0272 & 0.5146 \\
\hline Agaro & 1.2989 & 0.075 & 0.9569 & 0.1079 & -0.1062 & 0.5261 \\
\hline Ambo & 1.1755 & 0.0763 & 0.9146 & 0.1301 & -0.1432 & 0.4734 \\
\hline Arisi Adele & 1.3925 & 0.053 & 0.6841 & 0.1353 & -0.0282 & 0.6177 \\
\hline Arisi Robe & 1.4386 & 0.0588 & 0.804 & 0.0707 & 0.1724 & 0.7735 \\
\hline Ario & 1.4386 & 0.0588 & 0.81 & 0.0707 & 0.1724 & 0.74 \\
\hline Asosa & 1.3937 & 0.0566 & 0.88 & 0.0991 & 0.0899 & 0.61 \\
\hline Awassa & 1.4856 & 0.0207 & 0.36 & 0.1128 & 0.0652 & 0.21 \\
\hline Ayira & 1.4699 & 0.0641 & 0.93 & 0.1023 & 0.0726 & 0.52 \\
\hline Bale-Robe & 1.3399 & 0.0419 & 0.77 & 0.0895 & 0.0237 & 0.47 \\
\hline Bedelle & 1.4335 & 0.0462 & 0.87 & 0.0696 & 0.0244 & 0.27 \\
\hline "Bishoftu & 1.3497 & 0.0414 & 0.81 & 0.1284 & 0.0139 & 0.87 \\
\hline Bekoji & 1.4396 & 0.0359 & 0.77 & 0.1166 & -0.05 & 0.73 \\
\hline Ciroo & 1.4052 & 0.0576 & 0.94 & 0.1111 & 0.1175 & 0.83 \\
\hline Deder & 1.4179 & 0.0416 & 0.76 & 0.101 & 0.0564 & 0.52 \\
\hline Dembi-Dolo & 1.4033 & 0.0396 & 0.79 & 0.0765 & 0.0259 & 0.54 \\
\hline Fiche & 1.5358 & 0.0245 & 0.84 & 0.0848 & 0.0715 & 0.51 \\
\hline Garba-Guracha & 1.4567 & 0.0171 & 0.96 & 0.0636 & -0.1505 & 0.76 \\
\hline Gelemso & 1.3978 & 0.032 & 0.96 & 0.0936 & -0.0622 & 0.67 \\
\hline Gimbi & 1.4478 & 0.0602 & 0.88 & 0.1106 & -0.098 & 0.48 \\
\hline Ginnir & 1.3604 & 0.0338 & 0.7761 & 0.0936 & 0.1869 & 0.9712 \\
\hline Goba & 1.2609 & 0.0617 & 0.927 & 0.1296 & -0.1663 & 0.605 \\
\hline Gore & 1.47 & 0.0311 & 0.7384 & 0.0926 & -0.1251 & 0.755 \\
\hline Hagere-Mariam & 1.318 & 0.058 & 0.0884 & 0.0941 & 0.0146 & 0.0327 \\
\hline Haramaye & 1.4614 & 0.0394 & 0.9409 & 0.09931 & 0.1682 & 0.9658 \\
\hline Hunte & 1.3353 & 0.0501 & 0.7817 & 0.0881 & 0.0188 & 0.5503 \\
\hline Humuru & 1.4191 & 0.0521 & 0.8922 & 0.0997 & -0.097 & 0.5773 \\
\hline ljaji & 1.3476 & 0.0521 & 0.9138 & 0.0682 & 0.0615 & 0.6461 \\
\hline Jimma & 1.4339 & 0.0441 & 0.9634 & 0.0829 & -0.0854 & 0.8175 \\
\hline Kachisse & 1.4269 & 0.042 & 0.8875 & 0.0766 & -0.0916 & 0.6731 \\
\hline Kulumsa & 1.335 & 0.0419 & 0.6413 & 0.1299 & -0.0147 & 0.417 \\
\hline Mega & 1.2786 & 0.0468 & 0.9344 & 0.1416 & 0.0558 & 0.5219 \\
\hline Methehara & 1.3666 & 0.046 & 0.8087 & 0.1083 & -0.1072 & 0.7649 \\
\hline Mirab-Abaya & 1.3716 & 0.0508 & 0.9801 & 0.1408 & -0.1153 & 0.7257 \\
\hline Miesso & 1.421 & 0.015 & 0.8681 & 0.1157 & 0.0824 & 0.5883 \\
\hline Moyalle & 1.4499 & 0.0501 & 0.8724 & 0.0957 & -0.0938 & 0.5258 \\
\hline Negelle & 1.4284 & 0.0248 & 0.7289 & 0.0685 & 0.0554 & 0.2583 \\
\hline Nedio & 1.4035 & 0.0594 & 0.9386 & 0.0751 & 1366 & 0.719 \\
\hline Shambu & 1.4263 & 0.0541 & 0.9751 & 0.0853 & 0.0463 & 0.2127 \\
\hline Sinana & 1.2666 & 0.0863 & 0.9073 & 0.1396 & -0.0662 & 0.5946 \\
\hline Sokoru & 1.445 & 0.0381 & 0.9076 & 0.0841 & -0.0547 & 0.6691 \\
\hline Wolliso & 1.3893 & 0.0656 & 0.7955 & 0.0678 & -0.2076 & 0.5866 \\
\hline Yabello & 1.2585 & 0.0364 & 0.7614 & 0.1177 & -0.0278 & 0.1072 \\
\hline Zeway & 1.3542 & 0.0343 & 0.8808 & 0.1198 & 0.11 & 0.9376 \\
\hline
\end{tabular}

Moreover, the quantile function of the annual maximum rainfall depth series can be expressed in terms of its duration and recurrence interval by substituting the parameter-duration relationships into the inverse of cumulative distribution function. Recall that for EV1 distribution the inverse distribution function (quantile function) is given by:

$$
h_{T}(D)=\xi+\alpha y_{T}
$$

where $y_{T}$ is EV1 reduced vitiate and $\xi$ and $\alpha$ are location and scale parameters respectively. Accordingly, direct substitution of parameter duration relationship (20) in to EV1 quantile function (22) gives complete description of the EV1 quantile function give by;

$$
h_{T}(D)=\psi D^{\phi}+\beta D^{\rho} y_{T}
$$

Similarly, after substitutions and algebraic manipulations the complete description of the quantile functions of the logEV1 distribution can be expressed as:

$$
h_{T}=\sigma \theta^{y T} D^{\delta+z y_{T}}
$$

The quantile functions (23 and 24) are often referred to as the rainfall depth duration frequency relationships. The power law dependence of the distribution parameters and quantiles on the durations of extreme rainfall depth series shows that the extreme rainfall depth series exhibit scaling property with respect to the duration of occurrence. Recall also that the statistical investigation of extreme rainfall depth series confirms the multi scaling property of the rainfall depth series in the study region. While the rainfall depth duration frequency relationships 


\section{Megersa Tesfaye and Solomon Seyoum}

derived from multiple scaling behavior (equation 19) is very similar to the quantile function of the logEV1 distribution (equation 24), that derived from simple scaling property (6) has identical features with the quantile function of the EV1 distribution (equation 23). Therefore, the logEV1 distribution is the most appropriate frequency distribution for extreme rainfall depth series that exhibits multiple scaling properties.

\section{CONCLUSIONS}

One of the objectives of this study was to investigate the scaling properties of extreme rainfall depth series in the study region. The collected extreme rainfall depth series data were checked for consistency using mass curve analysis method; Test for independence were made by Fortran program based on (W-W) test; and the independency and consistency of the extreme rainfall depth series were confirmed. The study summarized the statistical properties of extreme rainfall depth series using an approach based on ordinary and L-moments, and detected important relationship between these statistics and durations of extreme rainfall depth series. The investigation revealed that the statistics of rainfall extremes vary systematically with duration. This variation of the statistics of rainfall extremes were used to investigate the scaling properties of the extreme rainfall depth series in the study region. The variation of distribution parameters with durations of annual maximum rainfall depth series were explored for different distributions. From the result it was confirmed that the EV1, logEV1 and logistic distribution parameters exhibited power law relationships with duration. Similar relationships were also obtained for location and scale parameters of GEV distribution while the shape parameter of GEV distribution was not related to the duration of extreme rainfall depth series. For the rest of the distribution functions tested in the region, power law relation did not exist. Furthermore from the logarithmic plots of ordinary moments and probability weighted moments versus duration for different moment orders at all stations, it was confirmed that power law scaling has existed.

From this, it was found out that the property of the time scale invariance of extreme rainfall quantiles in the study region follow a multiple scaling property. It was also found out that the investigated property of the extreme rainfall depth series has significant practical importance, because statistical extreme rainfall inference can be made to further develop a Depth Duration Frequency model that robustly explains the rainfall depth duration frequency relationship in the study region.

\section{REFERENCES}

Abbay River Basin Integrated Development Master Plan Project; Phase 2. Volume, III, April 1999.

Adamocuski, K. (1997). Regional analysis of annual maximum and partial duration flood data by non parametric and L-moment methods. Journal of Hydrology 229-231.

Ahmad, M.I., Sinclair, C.D. and Werrity (1988). A log- logistic flood frequency analysis. Journal of Hydrology 98: 215224.

Asires, G. and Semu, A. (2008). Development of intensity duration frequency relationship for Tigray and Amhara gerions. M.Sc Thesis, Arba Minch University, Ethiopia.
Sci. Technol. Arts Res. J., July-Sep 2014, 3(3): 122-131

Baldassare, G., Castellarin, A. and Brath, A. (2006). Relationships between statistics of rainfall extremes and mean annual precipitation: An application for designstorm estimation in North central Italy. Hydrology and Earth System Sciences 10: 189-601.

Bell, F.C (1969). Generalized rainfall duration frequency relationships. Journal of Hydrologic Division, ASCE 95(1): 311-327.

Bernand, M.M. (1932). Formulas for Rainfall Intensities of Long Durations. Transaction in ASCE 96: 592-624.

Bobee B. and Rasmussen (1998), Recent advances in flood frequency analysis. Journal of Hydrology 184: 47-49.

Burlando and Rosso. (1996). Scaling and multi-scaling models of depth duration frequency curves for storm precipitation. Journal of Hydrology 187: 45-65.

Chali. E. and Semu, A. (2007). Development of IDF for Oromia. M.Sc Thesis, School of Graduate Studies, Arba Minch university, Ethiopia.

Chaoche, K., Hubert, P. and Long, G. (2002), Geographical characterization of probability distribution. Stochastic Environment Research and Risk Assessment 16: 342357.

Chen, C.L. (1983). Rainfall intensity duration frequency formulas. Journal of Hydraulic Engineering, ASCE 109(12): 1603-1621.

Chow, V.T., Maidment, D.R. and Mays, L.W. (1988). Applied Hydrology, McGraw-Hill.

Coles and Pericchi (2003). A fully probabilistic approach to extreme rainfall modeling. Journal of Hydrology 273(1-4). 35-50.

Cunane, C. (1989). Statistical distribution for flood frequency analysis. World meteorological organization operational hydro. Rep. No.33, WMO publ.No.718, Geneva, pp.73.

Daly, A., Taylor, G.H. and Gibson, W.P. (1997). The PRISM approach to mapping precipitation and temperature, $10^{\text {th }}$ AMS conference on applied climatology, America Meteorological Society.

Datlymple, T. (1960). Flood frequency analysis, US geological survey, Reston.

Dingman, L.S. (2002), Physical Hydrology, $2^{\text {nd }}$ edition. Prentice-Hall. Inc. New Jersey.

Eagleson, P.S. (1970). Dynamic Hydrology, McGraw-Hill, New York.

Feleke, T. and Semu, A. (2002). Development of intensity duration frequency relationship for SNNP region. M.Sc Thesis, Arba Minch University, Ethiopia.

Fizgegland, D.L. (2007). Estimation of point rainfall frequencies. Irish meteorological service, Technical Note 61.

Foster. (1924). Assessing the effectiveness of hydrological similarity for frequency analysis, Journal of Hydrology 241(3-4).

Greenwood, J.A., Landwehr, J.M., Matalas, N.C. and Wallis, J.R. (1979). Probability weighted moments; Definitions and relation to parameters of several distributions expressible in inverse form. Water Resource Research 15(5): 1049-1054.

Gumbel, E.J. (1941). Statistics of Extremes. Colombia university press, New York. 